Corrigendum

\title{
Corrigendum to: Analysis of Cell Block and Cytology Specimen Preservation from Lung Aspiration Biopsy
}

\section{(Jurnal Kedokteran Brawijaya, 31(1): 23-27)}

Adinda Sandya $P^{1}$, Willy Sandhika ${ }^{2}$, Vicky Sumarki $B^{3}$

${ }^{1}$ Medical Study Program Faculty of Medicine Universitas Airlangga Surabaya

${ }^{2}$ Department of Anatomical Pathology Faculty of Medicine Universitas Airlangga Surabaya

${ }^{3}$ Department of Surgery Faculty of Medicine Universitas Airlangga Surabaya

We regrets that in the above published paper the following error occured.

The correction list have been provided in this corrigendum below.

\begin{tabular}{ccc}
\hline Page & Location & Correction \\
\hline 23 & article Correspondence & for “Adinda Sandya P. Medical Study Program Faculty of Medicine Universitas \\
& Airlangga Surabaya, Jl. Mayjen Prof. Dr. Moestopo No.47 Surabaya, Jawa Timur \\
& Tel.085755799005 Email: adinda.sandya.poernomo-2016@fk.unair.ac.id" read \\
& "Willy Sandhika. Department of Anatomical Pathology Faculty of Medicine \\
& Universitas Airlangga Surabaya Faculty of Medicine Universitas Airlangga \\
& Surabaya, Jl. Mayjen Prof. Dr. Moestopo No.47 Surabaya, Jawa Timur Tel. \\
& 08977474175Email: willysandh@gmail.com'
\end{tabular}

\section{P-ISSN : 0216-9347 E-ISSN : 2338-0772 Accredited by DIKTI Decree No: 23/E/KPT/2019}

Cite this as: Adinda Sandya $\mathrm{P}^{1}$, Willy Sandhika ${ }^{2}$, Vicky Sumarki B ${ }^{3}$. (2020). Analysis of Cell Block and Cytology Specimen Preservation from Lung Aspiration Biopsy. Jurnal Kedokteran Brawijaya, 31(1), 23-27; corrigendum, 31(2), 131. DOI: http://dx.doi.org/10.21776/ub.jkb.2020.031.02.12 